\title{
FORMULATION OF NOVEL WOUND HEALING HYDROGEL USING EXTRACTS OF PADINA TETRASTROMATICA AND DETERMINING ITS ANTIBACTERIAL ACTIVITY AGAINST WOUND PATHOGENS
}

\author{
${ }^{1 *}$ Ms.S.Oviya and ${ }^{2}$ Mrs. N.KARTHIHA* \\ ${ }^{1}$ MSc Student -Sri Ramakrishna College of Arts \& Science for Women \\ ${ }^{2}$ Assistant Professor -Sri Ramakrishna College of Arts \& Science for Women \\ ${ }^{1}$ ovidhanu23@gmail.com and $\underline{\text { 2karthihabio@srcw.ac.in }}$
}

\begin{abstract}
Seaweeds are rich in polysaccharides and also possess antiviral, antibacterial, antifungal, antiprotozoal, and antifertility activities. The present study covers about the effective wound healing and prevention by Hydrogel prepared from extracts of seaweeds. The seaweed was extracted with solvents and the crude extract was separated using analytical thin-layer chromatography (TLC). The separated compounds and prepared hydrogel were tested for their potential antibacterial activity and ant inflammatory activity against Staphylococcus aureus and Klebsiella pneumoniae bacteria. This study represented that the extracts of Padina tetrastromatica contain a variety of phytochemical compounds, which can effectively protect the body from inflammation and thus can be used as a potent source of natural protecting compounds.
\end{abstract}

Keywords: Hydrogel, Anti-inflammatory, TLC (Thin Layer Chromatography)

\subsection{INTRODUCTION:}

The seaweeds are collected from Rameshwaram, south coast of India. The alga Padina tetrastromatica, belongs to the order dictyotales of phaeophyta phylum, is found abundant in Indian coastal areas (Mohan et al., 2014). P.tetrastromatica was proved to be an upscale source of the foremost essential nutrients including vitamin B1, B2, B6, and minerals like copper, manganese, zinc, lead, etc. Padina tetrastromatica belongs to the Dictyotaceae family and is one among the foremost important marine brown seaweeds. Furthermore, Naqvi et al. 1(1981) investigated the biological activity of certain seaweeds from the Indian coast, including studies for antiviral, antibacterial, antifungal, antiprotozoal, and antifertility. A wound may be a relatively quick injury during which the skin is torn, cut, or punctured (an open wound), or a contusion is caused by blunt force trauma (a closed wound). It precisely refers to a pointy injury to the epidermis of the skin in pathology. Wounds that aren't healing should be investigated to seek out the causes; many microbiological agents could also be responsible. Diabetic foot 
wounds that don't heal are one among the foremost severe complications of diabetes, posing an enormous medical, social, and economic burden that features a direct effect on patient quality of life(Chakraborty et al., 2009)..

This study covers about the effective wound healing and prevention by Hydrogel prepared from extracts of seaweeds. For effective wound healing it requires an appropriate material to stop the wound infection. The emergence of antibiotic resistance in pathogenic microbes is major crisis within the global health problems. The algal tests were tested for his or her antibacterial activity against multidrug resistant isolates of bacteria. during this study multidrug resistant of three bacteria are used against wound pathogens. The deep wound may damage the integrity of skin and damage the tissues, it's essential to require care the injuries properly because it's going to cause severe problems which just in case not treated(Napeng et.al.,2019). Hydrogels are cross-linked polymers which will be natural or synthetic and are utilized in variety of biomedical fields. it's made from an insoluble polymer matrix with a water content of about 96 percent.

These hydrogels will donate water to the wound site, aiding within the preservation of a moist atmosphere that aids wound healing .Many scientists are now working towards Hydrogels within the areas of agriculture, food industry, tissue engineering, drug delivery and as regenerative medicine. Some sorts of hydrogels have inherent antibacterial activity. Recently Hydrogels are used due to their effectiveness and moist healing environment. Compared to other wound dressings Hydrogels are biodegradable, biocompatible and have low immunegenecity and straightforward usage. it's mainly wont to prevent and cure bacterial infections of wounds like burns, un healing wounds in diabetic patients ,tissue regeneration. There are various wound dressings to heal the injuries and to enhance health conditions but Hydrogels have unique compatibility that heal the injuries in moist environment, immediate pain relieving ,improved tissue repair and barrier against bacteria, oxygen permeability.

According to world health organization(WHO) the worldwide death rate is second place for the communicable disease . Hydrogels have increasing chemical, physical and biological properties compared to other dressings and even have a 3D cross linked polymer which may absorb and retain great deal of water. during this $\mathrm{TlC}$ is employed to isolate and purify the pigments from Padina tetrastromatica seaweed. This include extraction of seaweeds with optimized low polarity solvent mixtures, isolation of crude extract using analytical thin layer chromatography(TLC),biological screening of the extract for its antimicrobial activities by 
using TLC bio-autography. The hydrogel is ready by using seaweed extracts against multidrug pathogens like staphylococcus aureus, E.coli and klebsula pneumonia.(satarupa roy et.al.,2016).

\subsection{MATERIALS AND METHODS:}

\subsection{Collection of Padina tetrastromatica (Seaweed) and Authentication}

Padina tetrastromatica was collected from a shores of Rameshwaram, TamilNadu. It was authenticated by Dr. M.U. Sharief. Scientist 'E', Botanical Survey of India Southern Regional Centre, Coimbatore.

\subsection{Extraction of bioactive compounds using Soxhlet apparatus}

Padina tetrastromatica was dried under room temperature and finely grounded to powder. Powders of Padina tetrastromatica was placed in a porous bag or "thimble" made from a strong filter paper or cellulose, which is placed, is in thimble chamber of the Soxhlet apparatus. Extraction solvent (methanol) is heated in the bottom flask, vaporizes into the sample thimble, and condenses in the condenser and drip back. When the liquid content reaches the siphon arm, the liquid contents is emptied into the bottom flask again and the process is continued. For the study, infusion method of Soxhlet Extraction had been adopted. The dried powder was filled in the thimble and placed in the soxhlet extractor. The extractor had been filled with solvent solution of methanol and the temperature of $60^{\circ} \mathrm{C}$ was set and left for 6hours. The extracts were collected and the solvents were evaporated. The dried extracts were collected and stored in sterile containers.

\subsection{Phytochemical screening}

The methanolic extracts were subjected to qualitative phytochemical analysis.

\section{Alkaloids}

To $3 \mathrm{ml}$ test solution, a few drops of dilute iodine solution were added. Blue colour indicates the presence of alkaloids.

\section{Flavonoids}


Alkaline reagent test was performed for checking the presence of flavonoids. The crude powder was treated with a few drops of diluted sodium hydroxide $(\mathrm{NaOH})$ separately. Formation of intense yellow color which turned colorless on addition of a few drops of diluted $\mathrm{HCl}$ indicated the presence of flavonoids.

\section{Tannins}

$10 \mathrm{ml}$ of bromine water was added to the $0.5 \mathrm{~g}$ aqueous extract. Decoloration of bromine water showed the presence of tannins.

\section{Terpenoids}

Chloroform extract of the crude powder was treated with concentrated sulphuric acid (H2SO4). Appearance of reddish brown ring indicated the presence of terpenpoids.13

\section{Steroids}

Liebermann-Burchard reaction was performed for checking the presence of steroids. A chloroformic solution of the crude powder was treated with few drops of concentrated H2SO4 were added down the sides of the test tube. A blue green ring indicated the presence of steroids.

\section{Saponins}

The presence of saponins was determined by Frothing test. The crude powder was vigorously shaken with distilled water and was allowed to stand for $10 \mathrm{~min}$ and classified for saponin content as follows: no froth indicates absence of saponins and stable froth of more than $1.5 \mathrm{~cm}$ indicated the presence of saponins. 18

\section{Cardiac glycosides}

Keller-kiliani test was performed for checking the presence of cardiac glycosides. The crude powder was treated with $1.0 \mathrm{ml}$ mixture of $5 \% \mathrm{FeCl} 3$ and glacial acetic acid (1:99 v v1). To this solution, a few drops of concentrated $\mathrm{H} 2 \mathrm{SO} 4$ were added. Appearance of greenish blue colour within few minutes indicated the presence of cardiac glycosides

\section{Phenol}

$0.5 \mathrm{ml}$ of $\mathrm{FeCl} 3(\mathrm{w} / \mathrm{v})$ solution was added in $2 \mathrm{ml}$ of test solution, formation of an intense color indicates the presence of phenols.

\section{Quinones}

Extracts was treated with concentrated $\mathrm{HCl}$ appearance of green colouration indicates presence of Quinone.

\section{Test for Fixed oil (Filter paper test)}


A small quantity of the extracts was pressed between 2 two filter papers. Appearance of oil strain on the paper indicates the presence of fixed oils and fat.

\subsection{Preparation of wound healing gels}

Wound dressing gels was developed by the method described by Natarajan et al., 2018. Poly vinyl alcohol (2\%) is mixed with the distilled water and stirred under room temperature. Under stirring conditions $2 \%$ of seaweed extracts were added drop wise. $2 \%$ citric acid is added to the solution and stirred for 30mins. The films were poured in a plastic petri dish and kept undisturbed overnight. Later the gels were used for further analysis.

\subsection{TLC and anti bacterial activity against bioactive compounds}

The extracts were taken in a capillary tube and it was spotted in preparative TLC plates coated with silica gel G. The plates were developed in TLC chamber previously saturated with different solvent systems. The different spots developed in each solvent system were identified by means of detecting agent and the Rf value are correspondingly calculated 1,4.(Mobile phase : Butanol: Methanol: Water- 5:3:2).

\subsection{Antibacterial activity of the seaweed extracts and wound healing gel against wound causing pathogens}

The antibacterial efficacy of the seaweed extracts and wound healing gel was evaluated against the two major wound pathogen Staphylococcus aureus and Klebsiella pneumoniae by well diffusion method. Nutrient Agar was prepared and sterilized, and poured into plates. (Nutrient agar Composition (for $100 \mathrm{ml}$ ): Peptone: $0.5 \mathrm{~g}$; Yeast extract: $0.5 \mathrm{~g}$, Beef extract: $0.3 \mathrm{~g}$, Sodium chloride: $0.5 \mathrm{~g}$, Agar $1.5 \mathrm{~g}$; Total $\mathrm{pH}$ : $7.0 \pm 0.2$ ). Overnight cultures of test pathogens were cultured and $0.1 \%$ of culture solution of each test organisms was streaked throughout the petri plate with the sterile cotton swab by roating the plate at $60^{\circ}$ angle for each streaking. $6 \mathrm{~mm}$ well borer was used to bore wells on the agar surface of each NA plates. About $100 \mu$ of the samples were loaded into the well and the plates were incubated in an incubator at $37^{\circ} \mathrm{C}$ for 48h. The antibacterial activity was determined in terms of inhibitory zones around the wells loaded with natural dyes in all the Nutrient Agar plates containing test pathogens. The obtained clear zones were observed and measured in millimetre $(\mathrm{mm})$.

\subsection{Anti-inflammatory activity of the extract}


The anti-inflammatory activity of seaweed extract was studied by using inhibition of albumin denaturation technique which was studied according to Mizushima et al and Sakat et al followed with minor modifications. The reaction mixture was consists of test extracts and $1 \%$ aqueous solution of bovine albumin fraction, $\mathrm{pH}$ of the reaction mixture was adjusted using small amount of $1 \mathrm{~N} \mathrm{HCl}$. The sample extracts were incubated at $37^{\circ} \mathrm{C}$ for $20 \mathrm{~min}$ and then heated to $51^{\circ} \mathrm{C}$ for $20 \mathrm{~min}$, after cooling the samples the turbidity was measured at $660 \mathrm{~nm}$.( UVVisible Spectrophotometer Model 371, Elico India Ltd) The experiment was performed in triplicate. The Percentage inhibition of protein denaturation was calculated as follows:

Percentage inhibition $=($ Abs Control - Abs Sample $) \mathrm{X}$ 100/ Abs control

\subsubsection{Anti proteinase activity}

The test was performed according to the modified method of Oyedepo et al., 1995 and Sakat et al., 2010. The reaction mixture $(2 \mathrm{ml})$ was containing $0.06 \mathrm{mg}$ trypsin, $1 \mathrm{ml} 20 \mathrm{mM}$ Tris $\mathrm{HCl}$ buffer ( $\mathrm{pH} \mathrm{7.4)}$ and $1 \mathrm{ml}$ test sample of different concentrations $(100-500 \mu \mathrm{g} / \mathrm{ml})$. The mixture was incubated at $37 \mathrm{oC}$ for $5 \mathrm{~min}$ and then $1 \mathrm{ml}$ of $0.8 \%(\mathrm{w} / \mathrm{v})$ casein was added. The mixture was incubated for an additional $20 \mathrm{~min} .2 \mathrm{ml}$ of $70 \%$ perchloric acid was added to arrest the reaction. Cloudy suspension was centrifuged and the absorbance of the supernatant was read at $210 \mathrm{~nm}$ against buffer as blank. The experiment was performed in triplicate. The percentage inhibition of proteinase inhibitory activity was calculated.

Percentage inhibition $=($ Abs control - Abs sample $) \mathrm{X} 100 /$ Abs control

\subsection{RESULT}

\subsection{Phytochemical screening}

Preliminary phytochemical screening of Seaweed Padina tetrastromatica was carried out with aqueous extracts and the data was represented in table 1 . The extract was made out by using soxhlet apparatus methods. The preliminary phytochemical studies revealed the presence of alkaloids, steroids, glycosides and flavonoids in aqueous extract. Some phyto constituents were observed in aqueous extract viz., steroids, glycosides and flavonoids. Further, some phyto-constituents like alkaloids, steroids, glycosides, flavonoids and tannins were shown in 
aqueous extract. The resulting phytochemical analysis of Piper nigrum have shown in the Figure-1, Table.1.

Figure-1: Phytochemical screening of seaweed extracts

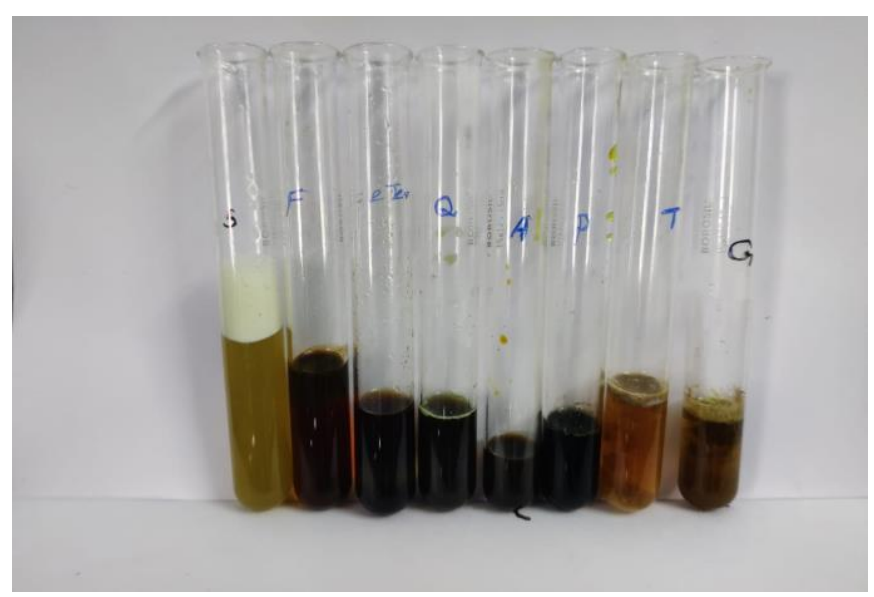

Table-1: Phytochemical screening

\begin{tabular}{|l|l|l|}
\hline S. No & Phytochemicals & Observation \\
\hline 1 & Alkaloids & - \\
\hline 2 & Flavonoids & + \\
\hline 3 & Saponins & + \\
\hline 4 & Tannins & + \\
\hline 5 & Steroids & - \\
\hline 6 & Terpenoids & + \\
\hline 7 & Phenol & + \\
\hline 8 & Glycosides & + \\
\hline 9 & Quinone & + \\
\hline 10 & Oil & \\
\hline
\end{tabular}

The presence and absence of the phytoconstituents in the seaweed Padina tetrastromatica shown positive(+ present). 
Preliminary phytochemical screening of seaweed Padina tetrastromatica clearly shows the presence of various phytoconstituents like flavonoids, terpenoids tannins, phenol, Quinone, oil, saponins .

\subsection{TLC and Antibacterial activity of bioactive compounds}

The seaweed padina tetrastromatica extracts were taken in a capillary tube and spotted in the preparative TlC plates with silica gel G. The plates were developed in TLC chamber which is saturated with solvent systems (mobile phase: Butanol: methanol :water -5:3:2). The spot expressed was seen under the uv light is shown in the figure 2.

\section{Figure -2 : TLC for extracts of seaweed Padina tetrastromatica}

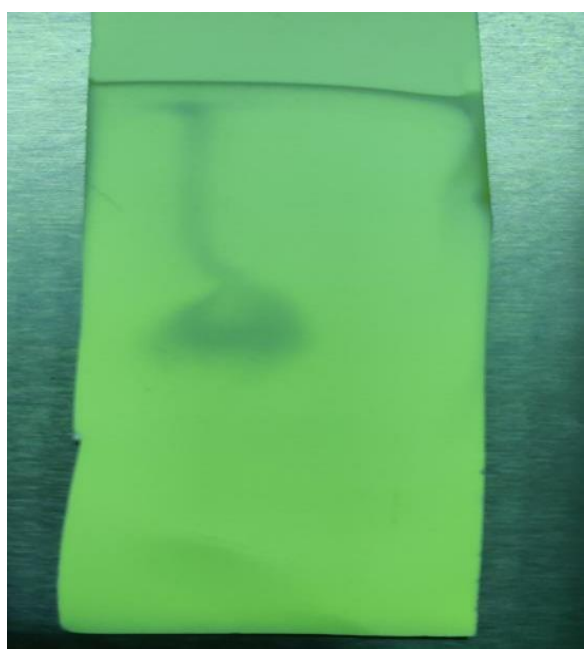

The antibacterial activity was performed for scrapped extracts from the TLC plates against the gram negative bacteria klebsula pneumoniae which is shown in the figure 3 and against one gram positive bacteria Staphylococcus aureus shown in figure 4.

\section{Figure -3 Antibacterial activity of Klebsula pneumonia}

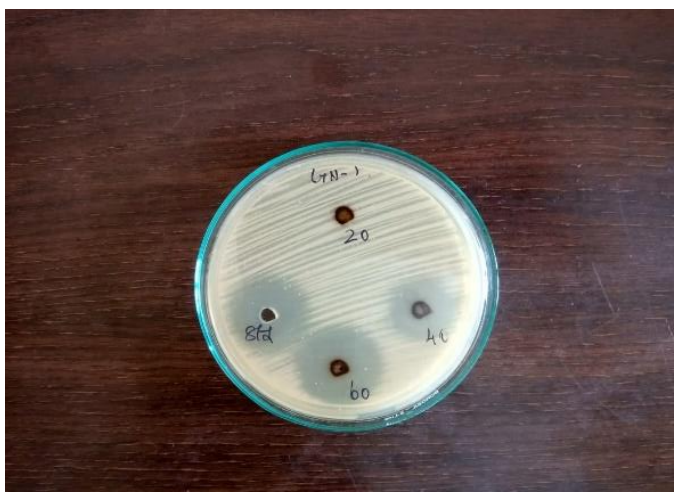


Figure -4:Anti-bacterial activity against Staphylococcus aureus

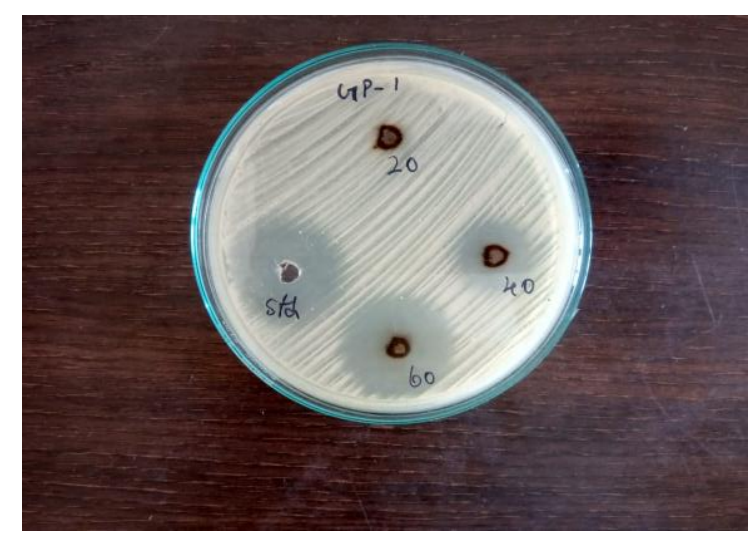

Table-2:Anti-bacterial activity of bioactive compounds

\begin{tabular}{|c|c|c|c|}
\hline \multirow{2}{*}{ S. No } & Sample & \multicolumn{2}{|c|}{ Inhibitory zones (mm) } \\
\cline { 2 - 4 } & & $\begin{array}{c}\text { Staphylococcus } \\
\text { aureus }\end{array}$ & $\begin{array}{c}\text { Klebsiella } \\
\text { pneumoniae }\end{array}$ \\
\hline 1 & $20 \mu \mathrm{g}$ & - & - \\
\hline 2 & $40 \mu \mathrm{g}$ & 12 & 13 \\
\hline 3 & $60 \mu \mathrm{g}$ & 15 & 17 \\
\hline 4 & Drug(ciproflaxin) & 16 & 14 \\
\hline
\end{tabular}

The above table shows at $20 \mu \mathrm{g}$ concentration the sample has no inhibitory zones against the bacteria Staphylococcus aureus and Klebsiella pneumoniae. The standard drug ciproflaxin shows $16 \mathrm{~mm}$ and $17 \mathrm{~mm}$, the $40 \mu \mathrm{g}$ concentration shows $12 \mathrm{~mm}$ and $13 \mathrm{~mm}, 60 \mu \mathrm{g}$ concentration of sample shows $15 \mathrm{~mm}$ and $14 \mathrm{~mm}$ inhibitory zones respectively against the bacteria Staphylococcus aureus and Klebsiella pneumoniae

\subsection{In-vitro Anti-inflammatory test}

The anti-inflammatory activity of seaweed Padina tetrastromatica extract was studied by using inhibition of albumin denaturation technique which was studied according to Mizushima et al and Sakat et al. As part of the investigation on the mechanism of the anti-inflammatory activity, extracts were effective in inhibiting process. The Percentage inhibition of protein denaturation was calculated as follows: 
Percentage inhibition $=($ Abs Control - Abs Sample $) \mathrm{X} 100 /$ Abs control

Table-3: Effect of seaweed extract on heat induced protein denaturation

\begin{tabular}{|c|c|c|}
\hline Concentration $(\boldsymbol{\mu g})$ & Absorbance at 660nm & $\begin{array}{c}\text { \% inhibition of } \\
\text { protein denaturation }\end{array}$ \\
\hline Control & 0.38 & - \\
\hline 100 & 0.25 & 34.21 \\
\hline 200 & 0.21 & 44.73 \\
\hline 300 & 0.17 & 55.26 \\
\hline 400 & 0.13 & 65.79 \\
\hline 500 & 0.10 & 73.68 \\
\hline
\end{tabular}

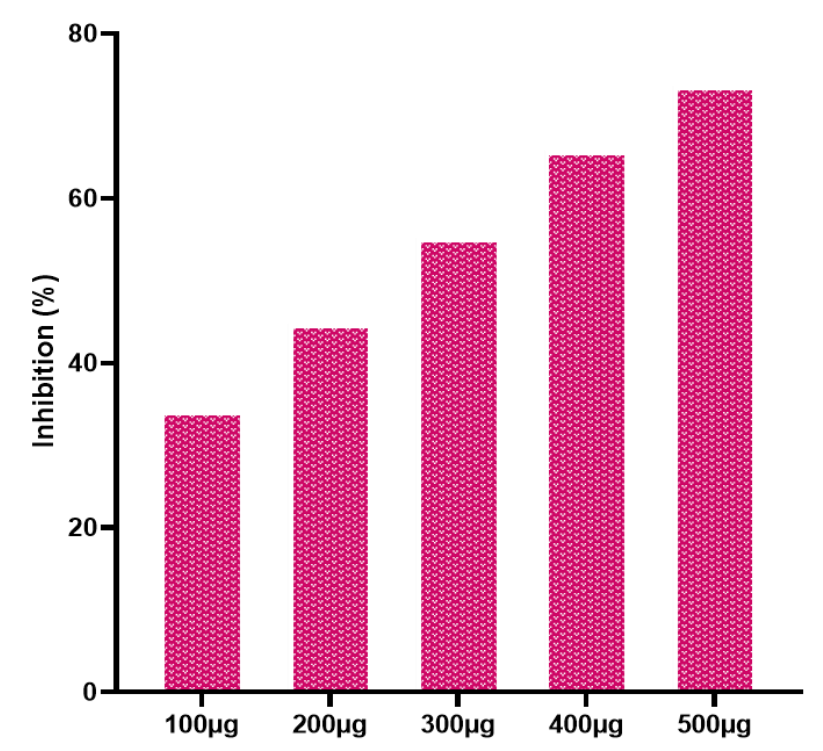

FIGURE - 5: A graphical representation of anti inflammatory activity

The above table and graph shows the seaweed Padina tetrastromatica extract at 100 to 500 $\mu \mathrm{g}$ it shows $34 \%$ to $73 \%$ inhibitory activity respectively, which is measured at $660 \mathrm{~nm}$.

\subsubsection{Anti-proteinase action}


The test was performed according to the modified method of Oyedepo et al., 1995 and Sakat et al., 2010. Cloudy suspension was centrifuged and the absorbance of the supernatant was read at $210 \mathrm{~nm}$ against buffer as blank. The experiment was performed in triplicate. The percentage inhibition of proteinase inhibitory activity was calculated.

Percentage inhibition $=($ Abs control - Abs sample $)$ X100/ Abs control

Table-4: Effect of seaweed extract proteinase inhibition

\begin{tabular}{|c|c|c|}
\hline Concentration $(\boldsymbol{\mu g})$ & Absorbance at 660nm & $\begin{array}{c}\text { \% inhibition of } \\
\text { proteinase }\end{array}$ \\
\hline Control & 0.38 & - \\
\hline 100 & 0.31 & 18.42 \\
\hline 200 & 0.29 & 23.68 \\
\hline 300 & 0.26 & 31.57 \\
\hline 400 & 0.24 & 36.84 \\
\hline 500 & 0.21 & 44.73 \\
\hline
\end{tabular}

\subsection{In-vitro Anti-bacterial activity}

The antibacterial efficacy of the seaweed Padina tetrastromatica extracts and wound healing gel was evaluated against the two major wound pathogen Staphylococcus aureus and Klebsiella pneumoniae by well diffusion method. About $100 \mu$ l of the samples were loaded into the well and the plates were incubated in an incubator at $37^{\circ} \mathrm{C}$ for $48 \mathrm{~h}$. The antibacterial activity was determined in terms of inhibitory zones around the wells loaded with natural dyes in all the Nutrient Agar plates containing test pathogens. The obtained clear zones were observed and measured in millimetre $(\mathrm{mm})$.

Figure-6: Antibacterial activity of seaweed extract and wound healing gel against $S$. aureus 


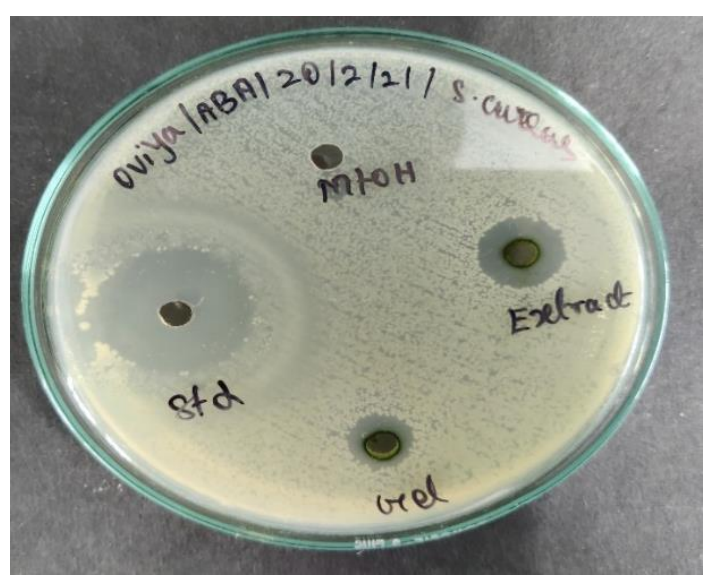

Figure-7: Antibacterial activity of seaweed extract and wound healing gel against $K$. pneumoniae

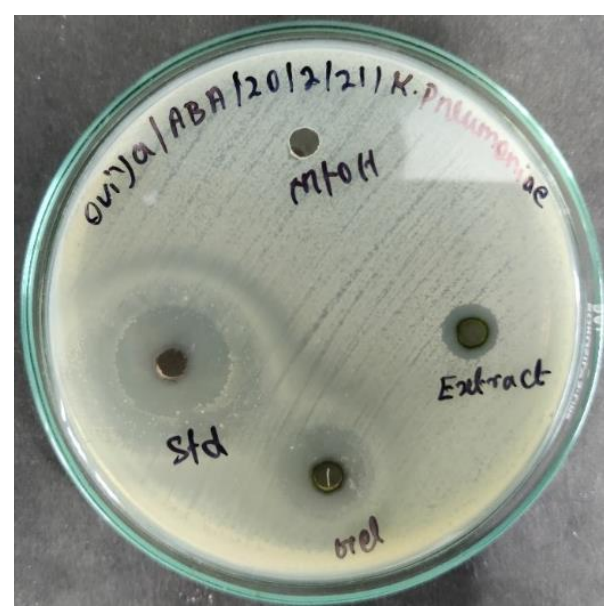

Table-5: Antibacterial activity of seaweed extract and wound healing gel

\begin{tabular}{|c|c|c|c|}
\hline \multirow{2}{*}{ S. No } & Sample & \multicolumn{2}{|c|}{ Inhibitory zones (mm) } \\
\cline { 3 - 4 } & & $\begin{array}{c}\text { Staphylococcus } \\
\text { aureus }\end{array}$ & $\begin{array}{c}\text { Klebsiella } \\
\text { pneumoniae }\end{array}$ \\
\hline 1 & Methanol & - & - \\
\hline 2 & Drug (Ciproflaxin) & 16 & 13 \\
\hline 3 & Extract & 10 & 10 \\
\hline 4 & Gel & 9 & \multicolumn{2}{c}{} \\
\hline
\end{tabular}


The above table shows plain methanol has no inhibitory zones against the bacteria Staphylococcus aureus and Klebsiella pneumoniae. The standard drug Ciproflaxin shows $16 \mathrm{~mm}$ and $13 \mathrm{~mm}$, the Padina tetrastromatica extract shows $10 \mathrm{~mm}$ and $8 \mathrm{~mm}$, the hydrogel shows $9 \mathrm{~mm}$ and $10 \mathrm{~mm}$ inhibitory zones respectively against the bacteria Staphylococcus aureus and Klebsiella pneumoniae.

\subsection{DISCUSSION:}

Hydrogels have existed for more than half century, providing one of the earliest records of crosslinked hydroxyethyl methacrylate (HEMA) hydrogels. Today,hydrogels still fascinate material scientists and biomedical researchers and great strides have been made in terms of their formulations and applications. As a class of material, hydrogels are unique, they consist of a self-supporting, water swollen three-dimensional (3D) viscoelastic network which permits the diffusion and attachment of molecules and cells. However, hydrogels have recently drawn great attention for use in a wide variety of biomedical applications such as cell therapeutics, wound healing, cartilage/bone regeneration and the sustained release of drugs. This is due to their biocompatibility and the similarity of their physical properties to natural tissue ( Chirani N, Yahia LH, Gritsch L, et al). In the previous work of Antonio francesko et.al. 2017 has reported that hydrogels are composed in a large extent of water and due to their non adhesiveness, it is used in wound dressing market and it provides a moisture environment for healing which is comfortable to the patient. The Hydrogel using are increases due to resemblance to dermal tissue and ability to induce partial skin regeneration. The innovation in advanced wound care is further directed to the development of so called active dressings, where hydrogels are combined with components that enhance the primary purpose of providing a beneficial environment for wound healing.

As we are discussed above there are numerous properties in seaweed Padina tetrastromatica which possess anti-viral,anti-bacterial,anti-inflammatory.anti-oncogenic,antitumor activity and also anti potent HIV agent. The hydrogels are having great unique properties and are prepared from many seaweeds and also as biofilms etc. The hydrogel prepared by using the extract of seaweed Padina tetrastromatica is first time. In this study we explore antibacterial activity of seaweed extract and wound hydrogel. Significant anti-bacterial activity is due to the prenence of several bioactive compounds in the padina extract . 


\subsection{CONCLUSION:}

Bacterial infection is a major reason for delayed wound healing, the development of drug resistant makes search for new anti bacterial compound. The phytochemical analysis have shown that the plant extracts possess flavonoids, tannins and steroids were present in aqueous extracts. In this study we explore antibacterial activity of Padina tetrastromatica extract and developed wound hydrogel. Both Padina tetrastromatica extract and gel shows better bacterial activity against major wound causing pathogens Klebsula pneumoniae and Staphylococcus aureus.

In the study represented that the extracts of Padina tetrastromatica contain a variety of phytochemical compounds, which can effectively protect the body from inflammation and thus can be used as a potent source of natural protecting compounds. In future, studies could be conducted to establish the anti inflammation mechanism of aqueous extract of sample. With all these results, we can conclude that Padina tetrastromatica can be used as a source of safe and natural protecting compounds against inflammation and can be used for treatment of prevention of wound infections. Significant anti bacterial is due to the presence of several bioactive compounds in this padina tetrastromatica extract. Moreover Padina tetrastomatica extracts also showed anti proteinase activity .Since padina tetrastromatica have more biological activities this will promote wound healing.

\subsection{REFERENCES:}

Chirani N, Yahia LH, Gritsch L, et al. History and Applications of Hydrogels.J Biomedical Sci. 2016, 4:2.

Shiau Pin Tana, P. M. (2013). Development of a novel antimicrobial seaweed extrac based hydrogel wound dressing. International Journal of Pharmaceutics.

Victor W.L. Ng, Julian M.W. Chan, Haritz Sardon, Robert J. Ono, Jeannette M. García, Yi Yan Yang, James L. Hedrick (November 2014). Advanced Drug Delivery Reviews journal homepage: www.elsevier.com/locate/addr

Shuqiang Li, Shujun Dong, Weiguo Xu, Shicheng Tu, Lesan Yan, Changwen Zhao,Jianxun Ding, and Xuesi Chen.. Antibacterial hydrogels Adv. Sci. 2018, 5, 1700527www.advancedscience.com 
GC-MS ANALYSIS, ANTIOXIDANT AND ANTIBACTERIAL ACTIVITY OF THE BROWN ALGAE, PADINA TETRASTROMATICA M. Uma Maheswari, A. Reena and C. Sivaraj Department of Microbiology, Mohamed Sathak College of Arts and Science, Chennai - 600119, Tamil Nadu, India. Armats Biotek Training and Research Institute INTERNATIONAL JOURNAL OF PHARMACEUTICAL SCIENCES AND RESEARCH

$\mathrm{Na}$ Peng, Xiongzhi Zhang, Huan Xu, Yi Liu. Polymeric Hydrogels with Antimicrobial Activity-A Review of Their Progress. Biomed J Sci \& Tech Res 23(5)-2019. BJSTR. MS.ID.003973.

Ng VW, Chan JM, Sardon H, Ono RJ, Garcia JM, et al. (2014) Antimicrobial hydrogels: a new weapon in the arsenal against multidrug-resistant infections .Adv Drug Deliver Rev 78: 46-62.

Li S, Dong S, Xu W, Tu S, Yan L, et al. (2018) Antibacterial Hydrogels. Adv Sci 5(5): 1700527.

Yang K, Han Q, Chen B, Zheng Y, Zhang K, et al. (2018) Antimicrobial hydrogels: promising materials for medical application. Int J Nanomed 13: 2217-2263.

Hoare TR, Kohane DS (2008) Hydrogels in drug delivery: Progress and challenges. Polymer 49(8): 1993-2007.

Antonio Franceskoa, Petya Petkovab and Tzanko Tzanov.Hydrogel dressings for advanced wound management(2017) DOI:10.2174/0929867324666170920161246

Chirani N, Yahia LH, Gritsch L,et al(2017). History and Applications of Hydrogels.Journal of Biomedical sciences ISSN 2254-609XJ. Biomedical Sci. 2016, 4:2.http://www.imedpub.com Tatyana A. Kuznetsova *, Boris G. Andryukov, Natalia N. Besednova, Tatyana S. Zaporozhets and Andrey V. Kalinin (2020) Marine Algae Polysaccharides as Basis for Wound Dressings, Drug Delivery, and Tissue Engineering:A Review ..A Journal of marine science and engineering. 
Pereira, L. Biological and therapeutic properties of the seaweed polysaccharides. Int. Boil. Rev. 2018, 2, 2 .

Dhivya, S.; Padma, V.V.; Elango, S.Wound dressings - a review. Biomedicine 2015, 5,22. Mariam Mir, Murtaza Najabat Ali, Afifa Barakullah, Ayesha Gulzar, Munam Arshad, Shizza Fatima, Maliha Asad (2018) . Synthetic polymeric biomaterials for wound healing: a review.

Frykberg RG, Banks J (2015) Challenges in the treatment of chronicwounds. Adv Wound Care 4(9):560-582. https ://doi.org/10.1089/wound .2015.0635

Jayachandran Venkatesan, Baboucarr Lowe, Sukumaran Anil , Panchanathan Manivasagan, Abdulaziz A Al Kheraif, Kyong-Hwa Kang and Se-Kwon Kim(2014). A review of Seaweed polysaccharides and their potential biomedical applications.

Laurienzo, P., Marine polysaccharides in pharmaceutical applications: An overview. Mar. Drug. 2010, 8, 2435-2465.

Andi Zhang, Ya Liu, Di Qin, Mengjie Sun , Ting Wang, Xiguang Chen(2020) . Research status of self-healing hydrogel for wound management :A review. International journal of biological macromolecules. http://www.elsevier .com/locate/ijbiomac

A. Gupta, M. Kowalczuk, W. Heaselgrave, S.T. Britland, C. Martin, I. Radecka, The production and application of hydrogels for wound management: a review, Eur.Polym. J. 111 (2019) 134-151.

Gaurav Rajauria and Nissreen Abu-Ghannam (2013). Isolation and Partial Characterization of Bioactive Fucoxanthin from Himanthalia elongata Brown Seaweed: A TLC-Based Approach Hindawi Publishing Corporation ,International Journal of Analytical ChemistryVolume 2013, Article ID 802573, 6 pages http://dx.doi.org/10.1155/2013/802573

Mohammad Sirousazara, Mortaza Yaric, Dehydration kinetics of Polyvinyl alcohol hydrogel wound dressings during wound healing process. Chinese Journal of Polymer Science Vol. 28, No. 4, (2010), 573-580.

Karolyn Barker, Shiva K. Rastogi, Jose Dominguez, Travis Cantu, William Brittain, Jennifer Irvin \& Tania Betancourt (2016) Biodegradable DNA-enabled poly(ethylene glycol) hydrogels 
prepared by copper-free click chemistry, Journal of Biomaterials Science,Polymer Edition, 27:1, 22-39, DOI: 10.1080/09205063.2015.1103590 